\title{
NEED FOR SAFETY IN DIFFERENT SOCIAL AND ECONOMIC GROUPS
}

\author{
Olga Yu. Zotova \\ University of the Humanities \\ Yekaterinburg
}

\begin{abstract}
The article gives an account of the empirical study results aimed at analyzing the degree of need for safety's satisfaction. The findings demonstrate that the degree of need for safety as a basic personality want strongly depends on gender, agerelated and professional distinctions.
\end{abstract}

Keywords: need for security, stability need, need for law and order, need for events predictability, need for stable and regularly paid job, need to be loved and desired, need to be protected from dangers of the hostile world, need for protection against real-life emergencies.

Over the past decades the psychological science has substantially increased interest to the issues of secure human existence. A necessity to look anew at the world and the place of a man in it forces researchers to seek new ways of thinking and solving ancient philosophical problems. The vector of social cognition is moving toward the phenomena related to the prevention of everyday life threats, and psychological and social security.

The need for security is one of anthropological symbols of human existence.

It is emerging along with the appearance of the human being and accompanies him/her throughout the entire human history. Ensuring security is a social experience, which is one of the most important for human beings. Ability to prevent threats, to form a security strategy is an indicator of social and cultural development of society, which indicates the humane nature of its political and ideological focus.

The idea of security reflects complicated processes in the "collective unconscious" of ethnic groups and in the structure of their archetypes.

The level of security is a specific indicator of the state of society, its beliefs about what is dangerous and what is safe, it reveals self-reflected society and its dominating values (Mozdakov, 2008). 
According to F. Ewald, in human society security is raised to the level of the basic values. Modern society raises both security and insecurity (Ewald, 1989, p. 393).

The need for security is one of the basic (Maslow, 2001) motivational mechanisms of human life inasmuch as of any other living creatures.

The evolution of humans has revealed a number of regularities by which the security function is characterized (Rodachin, 2004):

- social progress does not eliminate or preclude the danger to people individuals, society and state;

- increase of man's power over nature is accompanied by an increase in the scale of threats to humanity;

- the extent of differentiation of society and the complexity of its organization influences the expanding range of social risks;

- social threats are not fixed and are modified with the development of society;

- security is an essential attribute of complex social systems and institutions;

- underestimation or disregard of safety issues at all levels of social organization do not only cause losses, but eventually, inevitably leads to a decrease in viability (competitiveness), and even death of its corresponding units (entities).

Thus, security is a complex phenomenon. It is multidimensional and multifaceted by its structure, components and manifestations, and it reflects the conflicting interests in the relations of various social actors.

The need for security is the most important for a person whose satisfaction is a prerequisite for a normal existence and development, and implemented in the community through specific organizational forms, stable structures of social interaction, joint ventures, transforming into a system of interconnected personal and group interests and ways of achieving them.

Therefore, a human person wants to feel his/her connection with the surrounding world and with other people. They want to belong to a social group or a public structure. The need for security determines the desire of a person to be protected from destructive influences, providing internal resistance to these influences. The need for security is closely connected with feelings of psychological security, stability and confidence that a person feels relevantly. 
In the analysis carried out the most essential needs are combined into one group, which is the need for security, and includes the following aspects:

-stability need;

- need for law and order;

- need for events predictability;

- need for stable and regularly paid job;

- need to be loved and desired;

-need to be protected from dangers of the hostile world;

- need for protection against real-life emergencies.

We assume that the need for security is dependent on gender, age and occupation. To test this hypothesis we conducted an empirical study the purpose of which was to identify the degree of satisfaction of security need among representatives of different social and economic groups.

\section{Methodology}

To determine the degree of satisfaction of security needs were made up questions which are the starting point for further analysis and which include the following components of the security needs:

- needs of the organization, stability, law and order, predictability of events and in freedom from such threatening forces, as disease, fear and chaos.

Thus, these requirements reflect the interest in long-term survival:

- the need for security and protection when a person is faced with unpredictable events (war, flood, earthquake, riot, civil unrest, etc.).

During the process of working out the list of questions the following steps were taken:

1. The questions are formulated in accordance with the scale of five intervals of discharges.

2. The scale is as follows:

- "to a very large extent", "to a greater extent" the need for security is satisfied;

- "average" - average level of satisfaction of security needs;

- "to a lesser extent", "absolutely not" - the need for security is not satisfied. 
To determine the satisfaction of needs of human security questions which are basic for further analysis have been formulated.

\begin{tabular}{|l|l|c|c|c|c|c|}
\hline \multirow{2}{*}{ Tyo } & \multicolumn{1}{|c|}{$\begin{array}{c}\text { To a very } \\
\text { large } \\
\text { extent }\end{array}$} & $\begin{array}{c}\text { To a } \\
\text { greater } \\
\text { extent }\end{array}$ & $\begin{array}{c}\text { Ave- } \\
\text { rage }\end{array}$ & $\begin{array}{c}\text { To a } \\
\text { lesser } \\
\text { extent }\end{array}$ & $\begin{array}{c}\text { Abso- } \\
\text { lutely } \\
\text { not }\end{array}$ \\
\hline & +2 & +1 & 0 & -1 & -2 \\
\hline 1 & stability need & & & & & \\
\hline 2 & need for law and order & & & & & \\
\hline 3 & need for events predictability & & & & & \\
\hline 4 & need for stable and regularly paid job & & & & & \\
\hline 5 & need to be loved and desired & & & & & \\
\hline 6 & $\begin{array}{l}\text { need to be protected from dangers } \\
\text { of the hostile world }\end{array}$ & & & & & \\
\hline 7 & $\begin{array}{l}\text { need for protection against real-life } \\
\text { emergencies (war, social unrest) }\end{array}$ & & & & & \\
\hline
\end{tabular}

Questions of "Assessment of satisfaction with the person in need of security" questionnaire meet the following requirements:

- they fairly completely define the parameters under research and their structure;

- a limited number of questions allows in a relatively short period of time to question a large number of participants;

- simple structure of question form makes it equally comprehensible for all categories of participants;

- questions allow to create a standardized procedure of data processing;

- questions allow a relatively simple and unambiguous interpretation of the data.

The key to the "Assessment of satisfaction with the person in need of security" questionnaire is available:

\begin{tabular}{|l|l|}
\hline Total number of points & The degree of satisfaction with security needs \\
\hline From -9 to -14 & The need for security is not fully satisfied \\
\hline From -8 to -3 & The need for security is not satisfied \\
\hline From -2 to +2 & The need for security is satisfied partially \\
\hline From +3 to +8 & The need for security is $t$ satisfied \\
\hline From +9 to +14 & The need for security is $t$ satisfied to a greater extent \\
\hline
\end{tabular}


In this connection, the first phase of the pilot research was aimed at the selection and development of diagnostic tools to determine the degree of satisfaction of security needs.

Sample Participants. Sample participants $(650 \mathrm{pl})$ are equal by sex and educational level (48\% men and $52 \%$ women, $53 \%$ of them with higher education and $47 \%$ with secondary education).

They are divided into 4 age groups in accordance with D. Bromley's maturity periods: late youth (transition from dependence to independence) - from 18 to 21 years - 130 participants (20\%), early adulthood (involvement in all kinds of social activity) - from 21 to 25 years - 136 participants (21\%), middle adulthood (intellectual and professional activity peak) - from 25 years to 40 years - 169 participants (26\%), late adulthood (children leave parent families) - from 40 to 55 years - 215 participants $(33 \%)$.

Table 1

Qualitative composition of the sample under research

\begin{tabular}{|c|c|c|c|c|c|c|c|c|c|c|}
\hline Age & 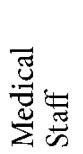 & 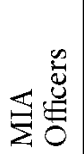 & & 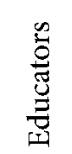 & 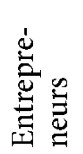 & 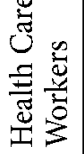 & 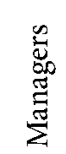 & 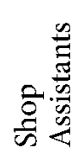 & 蔗 & 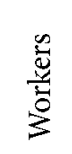 \\
\hline $18-21$ & $17 \%$ & $10 \%$ & $35 \%$ & $9 \%$ & $26 \%$ & $12 \%$ & $24 \%$ & $31 \%$ & $15 \%$ & $12 \%$ \\
\hline $21-25$ & $23 \%$ & $24 \%$ & $25 \%$ & $12 \%$ & $15 \%$ & $31 \%$ & $28 \%$ & $28 \%$ & $22 \%$ & $25 \%$ \\
\hline $25-40$ & $49 \%$ & $33 \%$ & $22 \%$ & $41 \%$ & $27 \%$ & $29 \%$ & $19 \%$ & $23 \%$ & $24 \%$ & $30 \%$ \\
\hline $40-55$ & $11 \%$ & $33 \%$ & $18 \%$ & $38 \%$ & $32 \%$ & $28 \%$ & $29 \%$ & $18 \%$ & $39 \%$ & $33 \%$ \\
\hline $\begin{array}{l}\text { Number } \\
\text { of person }\end{array}$ & 75 & 70 & 105 & 81 & 80 & 66 & 86 & 87 & 51 & 45 \\
\hline
\end{tabular}

Procedure. The participants were asked to scan the list of questions "Evaluation of satisfaction with the person in need of security".

Then they were to answer the questions at any time which was convenient for them.

Processing of Experimental Results. The raw data are tabulated by the matrix and processed in accordance with the prescribed rules of counting performance. Further statistical analysis of the results was carried out in accordance with the basic hypothesis of the research. 


\section{Results Analysis}

In accordance with the results it has been identified that the need for security among the participants is satisfied only partially (expected value of 0.72 points for the entire number of sample participants), which suggests that in relatively stable social conditions, the need for security of a regular individual is satisfied to a lesser extent or is taken by the participant as satisfaction.

In such cases, being an active factor for determining the motivational sphere of a person, the need for security is practically not fixed and may be manifested, for example, as mere preference for familiar behaviour and life situations with well-defined (sharp enough) future perspectives, which involve lots of elements of uncertainty, desire for more stable conditions of living, etc.

Analysis of the research results shows that within the structure of the security needs the absolute priority belongs to the need to be loved and desired (expected value of 1.17 points on a scale from -14 to +14 ).

To some extent, the proximity of other results causes reduction of anxiety, mitigating the impact of physiological and psychological stress.

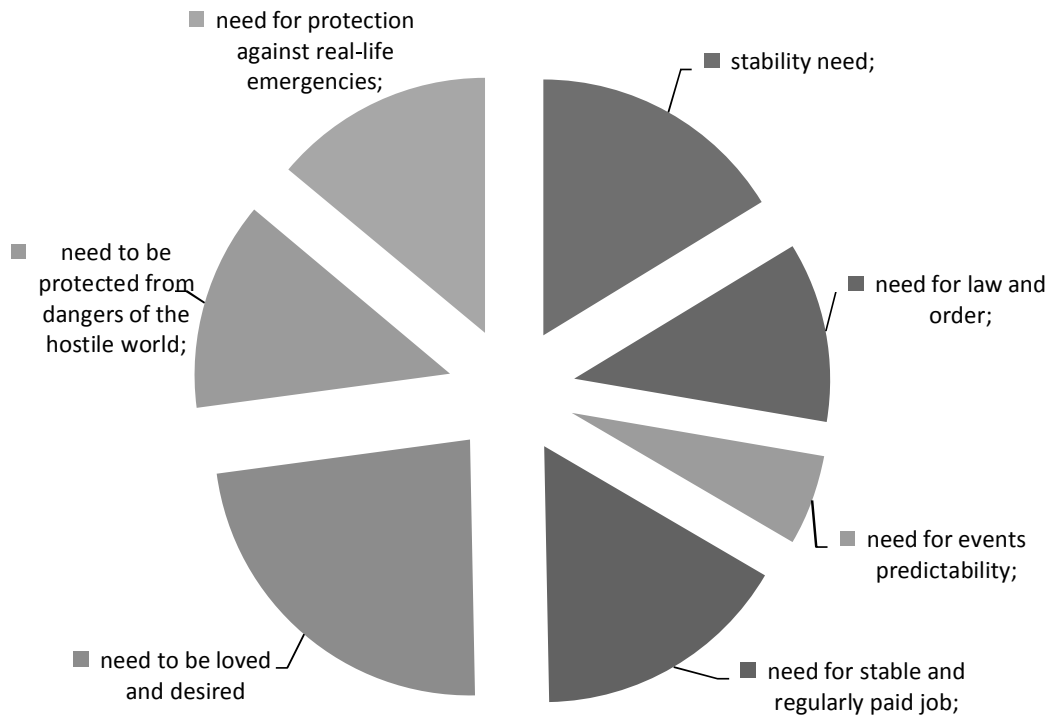

Figure 1. Share of Types of Security Needs in Participants 
Need to be loved is adjacent with the need for stability and the need for stable and regularly paid job (expected value of 0.82 and 0.81 points respectively).

In contrast with the above mentioned the level of the minimum values is characterized by only one position. It is the need for events predictability (expected value of 0.28 points). The lowest scores for this position allow us to conclude that rapid changes in today's life lead to a deep insecurity in people and gives rise to a strong need for predictability.

"The deep uncertainty about the future contributes to the need for strong authority that would protect them from threatening forces, and also xenophobic views. Frightening rapid change gives rise to intolerance to cultural changes and to alien ethnic groups" (Inglehart, 1997, p. 18).

It is the deprived need for security that comes to the fore and becomes the leading one; it becomes the determining factor of motivation for human social behaviour, rearranging and changing it, transforming other basic needs, psychological characteristics and personality traits in a specific way.

As it has been mentioned by a number of researchers, it becomes an active and dominant resources mobilizer in the human body under such unpredictable circumstances as social disorganisation, natural catastrophes, criminal assault, natural disasters, etc. Evaluation ratings of five other needs are determined at the average level of significance (from 0.5 points and above this point).

Thus, the need for security as an internal resource of a person has a distinct orientation toward personal well-being (love, family, and joy), where the fundamental motive is the need to be loved, desired and protected from dangers of the hostile world.

Comparative analysis of male and female participants revealed differences of security needs in the hierarchy and the degree of satisfaction.

Statistic significant differences $(\mathrm{p}<0,05)$ were found only in this part of the scale which deals with the need for security, such as the desire to be protected from dangers of the hostile world.

It is these needs that play a significant role in the structure of the "female" components of the security needs of a higher role than in the structure of the "male" ones.

In addition to these statistic significant differences other albeit less pronounced ones shall be highlighted. They are the needs for security in males and females whose data are indicated by average values (Fig. 2). 


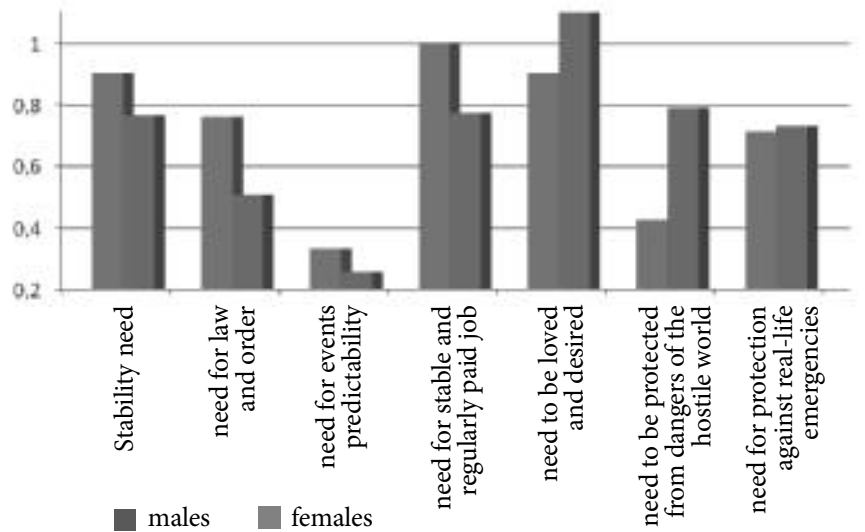

Figure 2. Values of Security Needs in Male and Female Participants

To the already mentioned above needs, we can also add the need for reliable performance and stability, which receive great satisfaction in male representatives, and the need for the law and order. At the same time the need to be loved and desired is expressed to a higher degree in women. In the most status-neutral, i.e. equally represented in the structure of the "male" and "female" need for security was the need for protection against real-life emergencies. Analysis of degree variability of satisfaction with security needs in different age groups allows us to see the dynamics of sense of comfort, safety and security, depending on the process of maturation (Fig. 3).

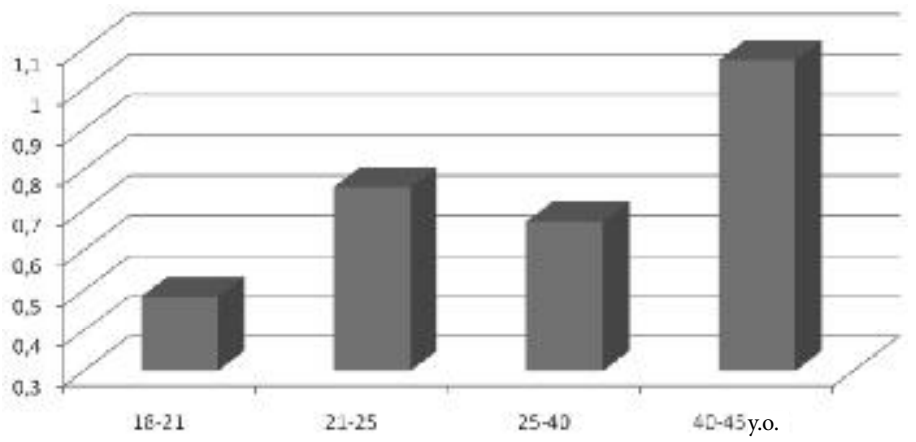

Figure 3. Dynamics of Security Need Satisfaction in Age Groups 
Thus, in the youngest age group (18-21 years) the degree of satisfaction with security needs has achieved the lowest value ( 0.48 points), due to the fact that at this age young people are perceived by the public and themselves as novices in the adult world. During this period, they try to resolve the conflict between the need to explore the opportunities of the adulthood, and the need to establish a stable life structure. In this way, the life structure in early adulthood does not give a full sense of stability and permanence. In the next age group (21-25 years) we observe an increase in the degree of safety satisfaction while in the age group of 25-40 years there has been some decrease in satisfaction with security needs, which is probably associated with the maximum expression of the importance of financial security which is caused by the objectively high financial needs. At the age of 40-45 years, the need for security is satisfied to the maximum extent that clearly demonstrates the desire to stability. This is most likely connected with a change in self-perception of individuals in this age, whose need for achievement in many ways has already been granted and they are increasingly moving to a "defense" and protection of what they have already got in possession.

The result analysis shows that the degree of satisfaction of security needs in different age and occupational groups is different (Fig. 4).

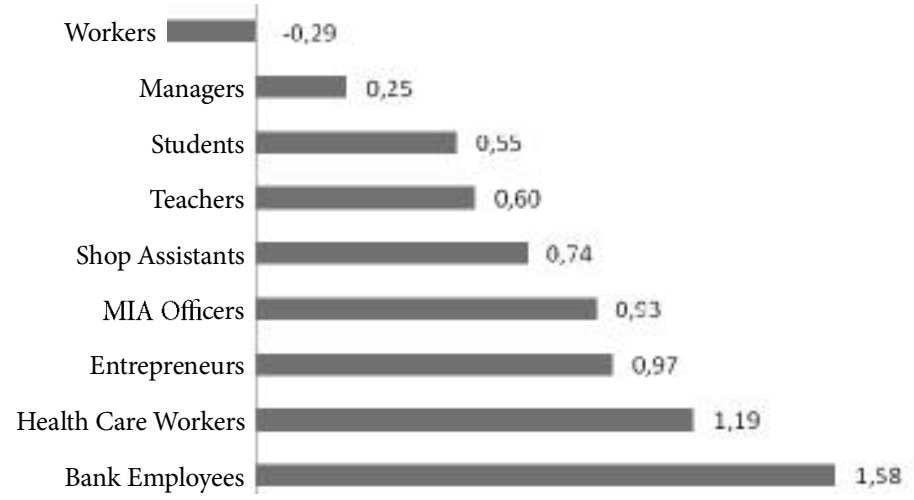

Figure 4. Security Need Satisfaction in Members of Different Occupational Groups

Thus, the most satisfied need for security is observed in bank employees (1.58 points), followed by health care workers (1.19 points). 
It can be assumed that a steady job and a stable income give a sense of security and relative safety. The need for security is not satisfied in the workers ( -0.28 points), which causes anxiety, deep inner conflict, difficulties in self-fulfillment and also psychological barriers when trying to disclose inner potential. The need for safety is satisfied to the highest degree in entrepreneurs (1.18 points), which is probably related to the particular features of their activity, which presupposes such qualities as rationality, tendency to planning, self-confidence, willingness to overcome obstacles, optimism, faith in their abilities. At the level of the minimum values given we observe this type of need in workers $(-0.44$ points).

Table 2

Values of Types of Security Need in Different Occupational Groups

\begin{tabular}{|c|c|c|c|c|c|c|c|c|c|c|}
\hline № & $\begin{array}{l}\text { Types of } \\
\text { Security Needs }\end{array}$ & 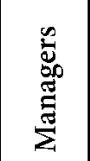 & 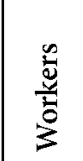 & 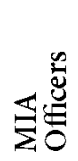 & 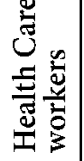 & 窇苛 & $\frac{\infty}{\mathscr{E}}$ & 节 & 冚 & 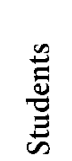 \\
\hline 1 & Stability need & 0,63 & $-0,44$ & 1,2 & 0,90 & 1,18 & 0,63 & 0,81 & 1,54 & 0,90 \\
\hline 2 & $\begin{array}{l}\text { Need for law and } \\
\text { order }\end{array}$ & $-0,27$ & $-0,64$ & 1 & 0,81 & 1,09 & 0.27 & 0,90 & 1,63 & 0,36 \\
\hline 3 & $\begin{array}{l}\text { Need for events } \\
\text { predictability }\end{array}$ & 0,27 & $-0,62$ & 0,3 & 0,54 & 0,27 & 0,45 & 0,18 & 0,63 & 0,54 \\
\hline 4 & $\begin{array}{l}\begin{array}{l}\text { Need for stable and } \\
\text { regularly paid job }\end{array} \\
\end{array}$ & 0,54 & $-0,51$ & 1,3 & 1,27 & 1,27 & 0,81 & 0,81 & 1,72 & 0,18 \\
\hline 5 & $\begin{array}{l}\text { Need to be loved } \\
\text { and desired }\end{array}$ & 0,63 & 0,11 & 1,3 & 1,81 & 1,45 & 1,36 & 1,09 & 1,90 & 0,90 \\
\hline 6 & $\begin{array}{l}\text { Need to be protec- } \\
\text { ted from dangers } \\
\text { of hostile world }\end{array}$ & 0,18 & $-0,32$ & 0,7 & 1,63 & 0,72 & 0,18 & 0,81 & 1,72 & 0,36 \\
\hline 7 & $\begin{array}{l}\text { Need for protec- } \\
\text { tion against real- } \\
\text { life emergencies }\end{array}$ & $-0,27$ & 0,31 & 0,7 & 1,36 & 0,81 & 0,45 & 0,54 & 1,90 & 0,54 \\
\hline
\end{tabular}

Evaluation ratings of the need for law and order among the considered occupational groups are as follows: this need is satisfied to the upmost degree in entrepreneurs and employees of the Interior Ministry, and it is satisfied to the lesser degree in the managers and workers. The 
need for stable and regularly paid job is satisfied in the employees of the Interior Ministry, the need to be loved and desired is satisfied in teachers, the need to be protected from dangers of the hostile world is satisfied in health care workers. So, the most prosperous in terms of meeting the needs of security among the participants are entrepreneurs and employees of the Interior Ministry, and those ones who are satisfied to the lesser degree are workers.

Analysis of the component of deprivation among representatives of different social and economic groups is given a lot of importance. Lack of adequate capacity to meet the needs of this group may cause negative mental state, against which all the mental processes occur. It is the deprived need which determines social behaviour by its integral effect.

Therefore, in professional group of managers the need for law and order and protection from real-life emergencies turns out to be deprived. In workers the majority of components of the security needs is deprived, except for the needs to be wanted and loved and needs to be protected from real emergencies.

In this way, the most disadvantaged in terms of meeting basic needs for security is the group of workers which leads to the lack of stability, confidence, and eventually the lack of psychological security.

\section{Conclusion}

Thus, the research carried out provides a basis for concluding that the need for security among the participants is satisfied only partially, which may be associated with the rapid changes of social life, its political and organizational structure. It may lead to a general loss of the system of social protection and, consequently, reduces psychological resource resistance to the adverse effects of human environment.

The highest degree was detected in a component of security needs as the need to be loved and desired, which reflects the trend to be satisfied with the family welfare by the majority of the participants. This tendency suggests the importance of mutual understanding and cordial relations with family and friends.

In the category of the mostly deprived needs the participants mentioned the need of the events predictability which is probably associated with tragic events, for example, acts of terrorism in various countries, including Russia, escalating violence in intergroup and interpersonal 
interaction. When examining the degree of satisfaction with the basic needs of security there occur features particularly related to sex, age and occupational differences. The need to be protected from dangers of the hostile world is more characteristic of women, while the need for stable and regularly paid job is typical for men, which is completely justified by an archaic approach to men and women. The most archaic need for women is to be protected. This expectation with respect to a male is characteristic of a female and refers to her instinctive manifestations. Data analysis in occupational groups shows that the need for security is to a larger extent is revealed in bank employees and health care workers, while the position of workers is a strong stressor, and their need for security is deprived.

In this country, we can also observe various forms of implementation of the need for security and other related needs, some of which are highlighted by Erich Fromm. These include, for example, such socially transformed shapes to satisfy these needs as participation in dangerous activities and membership of organized crime structures, the nationalist associations, etc. Sometimes when experiencing very vaguely or acutely the inability to meet their own needs for security and thus create conditions for normal physical and spiritual development a person feels faced with his/her problem alone.

E. Fromm draws attention to the social and psychological grounds of personal relationship, group involvement in the social and semantic systematic approach: "...by being aware of himself as distinct from nature and other people, by being aware - even very dimly - of death, sickness, ageing, he necessarily feels his insignificance and smallness in comparison with the universe and all others who are not 'he'. Unless he belonged somewhere, unless his life had some meaning and direction, he would feel like a particle of dust and be overcome by his individual significance. He would not be able to relate himself to any system which would give meaning and direction to his life, he would be filled with doubt eventually would paralyse his ability to act - that is, to live" (Fromm, 1989, p. 28). 


\section{References}

Ewald, F. (1989). Die Versicherungs-Gesellschaft. Kritische Justiz, 22. 385-393.

Fromm, E. (1989). Begstvo ot svobody [Escape from Freedom]. Moscow: Progress. Inglehart, R. (1997). Postmodern: menjajuschiesja cennosti i izmenjajuschiesja obschestva [Postmodemity: Changing Values and Changing Societies]. Polis, 4, 6-32.

Maslow, A. (2001). Motivacija i lichnost' [Motivation and Personality]. St.-Petersburg: Evrazija.

Mozdakov, A.Ju. (2008). Socialno-filosofskie aspekty problemy bezopasnosti [Sociophilosophical aspects of security]: diss. ... kand. filos. nauk. Velikij Novgorod.

Rodachin, V.M. (2004). Bezopasnost' kak social'noe javlenie [Security as social phenomenon]. Pravo i bezopasnost', 4(13), 14-17. 